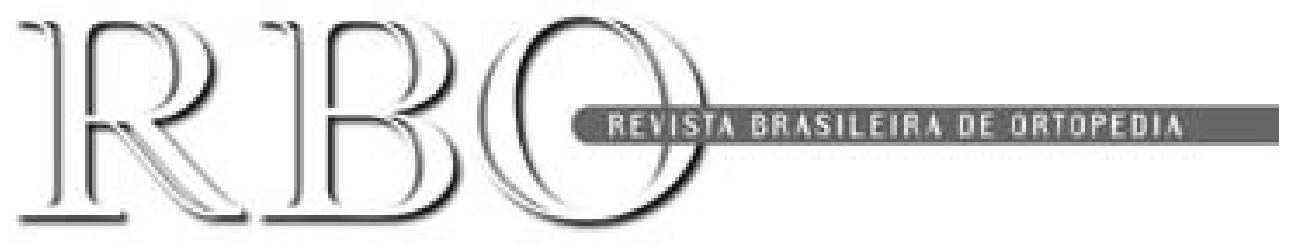

\title{
Editorial
}

\section{A vocação da RBO: 70 anos de apoio ao ortopedista brasileiro}

\author{
The task of RBO: 70 years of support to the Brazilian orthopaedic surgeon
}

A história desta Revista Brasileira de Ortopedia transcreve boa parte da trajetória da ortopedia brasileira. Considerada uma das pedras fundamentais da Sociedade Brasileira de Ortopedia e Traumatologia (SBOT), a revista foi, com muita dificuldade, alavancada ao público numa época em que a especialidade dava seus primeiros passos no Brasil, mas já trazendo em seu âmago a missão da divulgação científica. Hoje, tem duplo papel, como bem afirmou Gilberto Camanho em seu primeiro editorial de 2009: o de contribuir com a atualização científica de mais de 10 mil ortopedistas no Brasil, onde é editada, e o de atingir o mundo por meio da indexação científica - esta também uma prova de sua qualidade científica.

Como já escrevemos alhures, José Londres, em carta de articulação para fundação da SBOT, dizia: “Quero crer que seria conveniente formar-se uma Academia, com número limitado de membros efetivos, todos especialistas, se possível. A seguir, cuidar-se-ia da publicação trimestral de uma revista, aberta à colaboração de todo trabalho de interesse da especialidade, mesmo que o seu autor não seja membro da organização". Essa carta data de agosto de 1935, um mês antes da fundação da SBOT, e marca de forma indelével a vocação da sociedade de promover a produção da ciência e de divulgá-la aos pares.

O Arquivos Brasileiros de Ortopedia, editado no ano seguinte por Barros Lima, um dos fundadores da SBOT, trazia os anais do I Congresso da sociedade. Preservado nos arquivos da SBOT até hoje, esse volume de 1936 pode ser considerado a semente da atual RBO. Achilles Araújo, também fundador da SBOT, criou a RBO apenas três anos depois. Restam pouquíssimos exemplares dessa primeira edição da RBO no Brasil. No texto de apresentação, Achilles escreveu (mantida a grafia original):

“Com o presente fasciculo, inicia a 'Revista Brasileira de Orthopedia e Traumatologia' a tarefa a que se propoz - ser o repositorio e ao mesmo tempo a divulgadora da producção scientifica dos que entre nós se dedicam ao estudo desses assumptos e uma collaboradora dedicada e enthusiasta da obra que vem brilhantemente realizando a Sociedade Brasileira de Orthopedia e Traumatologia em pról do conceito de autonomia dessas especialidades que se completam.

O numero sempre crescente de trabalhos scientificos sobre a pathologia e a clinica dos orgãos do apparelho locomotor, dispersos em numerosos periodicos de medicina do paiz e mesmo do extrangeiro, mostra exuberantemente o interesse que vem dispertando, em nosso meio, a especialidade, e a necessidade, para melhor aproveitamento do esforço dos que a ella se dedicam, de unil-os numa revista que tenha por escopo unico occupar-se desses assumptos.

A 'Revista Brasileira de Orthopedia e Traumatologia' apparece como uma consequencia logica dessas affirmativas e está certa que, reunindo e divulgando a producção technico-scientifica dos cultores da especialidade no Brasil, e tornando-se, como deseja, campo efficiente de estudo dos multiplos e complexos problemas medico-sociaes que a Orthopedia e a Traumatologia ainda apresentam, está certa, repetimos, que fará obra util e patriotica".

Sábias palavras. O professor Achilles, que presidiu a SBOT entre 1936 e 1937, comprometeu a vida toda com a divulgação da especialidade, e editou e manteve, sozinho, a Revista até 1945. Infelizmente, uma grande lacuna nos registros históricos se segue até 1965, quando se volta a discutir a necessidade de um espaço oficial de divulgação dos trabalhos científicos em ortopedia. Vinte anos sem RBO. Faltava estruturação e financiamento para tal obra e, 
durante o Congresso da SBOT realizado em Belo Horizonte em 1967, Márcio Ibrahim de Carvalho propôs editar a revista na Imprensa da Universidade de Minas Gerais. Para isso, precisava da autorização do "proprietário" do título, Achilles Araújo, que prontamente a concedeu, e de dinheiro.

Estudos anteriores apontavam que seria impossível voltar a publicar a RBO sem fundos. Ficou então decidido em reunião executiva que um terço das contribuições dos sócios da SBOT (menos de 300 ortopedistas naquela época) seria reservado para a revista. Uma sábia decisão política. O primeiro número dessa nova fase da RBO saiu com a menção, na capa: "Fundada por Achilles de Araújo". Foi feita uma campanha para levantar fundos para os primeiros números, com o sorteio de dois carros, e o lançamento oficial ocorreu em 9 de dezembro de 1966 no saguão da Biblioteca da Faculdade de Medicina da Universidade Federal de Minas Gerais (UFMG).

A Biblioteca da Faculdade de Medicina da UFMG foi sede da RBO durante cinco anos, enquanto Márcio Ibrahim permaneceu como seu editor. Donato D'Angelo, outro grande colaborador da SBOT, assumiu então seu lugar em 1972 e dirigiu a revista por nada menos que 27 anos. O seu próprio consultório no Rio de Janeiro era a sede da RBO nesse período. Presidente do XX Congresso da SBOT, realizado em 1975, Donato usou dessa experiência para resolver outro problema da RBO, além da crônica falta de recursos econômicos: a escassez de artigos para publicação. A revista publicou três fascículos anuais entre 1971 e 1977. Toda essa produção veio dos trabalhos apresentados nos Congressos Brasileiros de Ortopedia e Traumatologia (CBOT) e do exame para obtenção do Título de Especialista em Ortopedia e Traumatologia (TEOT) - de cuja Comissão Donato também fazia parte. Assim, para obter o TEOT o candidato precisava produzir, e essa produção, quando obtinha nota acima de 8 , gerava publicação. Os trabalhos apresentados nos CBOTs também tinham espaço garantido na RBO. Além disso, Donato articulava com chefes de serviço, solicitando a redação de artigos. Sem as regras atuais de avaliação científica, muitas vezes um trabalho era selecionado pelo seu tamanho, conforme era a necessidade de um artigo "maior" ou "menor"!

A partir de 1978, Donato também iniciou parcerias com gráficas que imprimiam a revista, dando-lhes o direito de vender anúncios na RBO, como parte de cobrir os custos de produção. Naquele ano, a revista passou a sair com quatro fascículos anuais. E não parava de crescer: a partir de 1982, seis números anuais. Em 1981, conseguiu a indexação na base de dados Lilacs, da América Latina. Em 1987, a revista precisou solicitar ajuda a agências de fomento à pesquisa, como a Finep e o CNPq, para conseguir publicar a RBO, já que os laboratórios anunciantes retiraram as verbas devido à crise econômica. No ano seguinte, a RBO já saiu com 10 edições. Em 1999, por decisão do presidente da SBOT, Edison José Antunes, a RBO saiu com seu fascículo regular e mais um, dedicado aos comitês de subespecialidades. Em 1996, a produção dos comitês permitiu aumentar o número de edições para 12 anuais. Em 1999, com um fenomenal rosário de ações dedicadas à ortopedia brasileira, Donato D'Angelo pediu para desligar-se da RBO, tornando-se Editor Emérito.

Carlos Giesta assumiu seu lugar e elaborou o Regimento Interno da RBO naquele mesmo ano, modificando os critérios de seleção dos artigos para publicação, para assegurar maior qualidade. Foi criada a Comissão Executiva da revista e o Corpo Editorial foi reestruturado e ampliado. Em 2003, a revista começou a publicar artigos também em inglês. Em 2004, todo o conteúdo da revista a partir de 1993 foi publicado na internet. A partir de 2005, a escolha do editor-chefe passou a ser feita entre os pares do Corpo Editorial (em vez da tradicional indicação pelo presidente da SBOT). Os artigos de revisão de temas atuais solicitados pessoalmente aos líderes da ortopedia nacional publicados no início da edição, e as cartas e editoriais escritos com rebuscados recursos linguísticos também marcaram a influência de Giesta na RBO.

Em 2007, a revista conseguiu dar mais um importante passo no sentido de aumentar sua visibilidade internacional: foi indexada pela base de dados SciELO (Scientific Electronic Library Online), que disponibiliza todos os textos integralmente e de graça.

Em 2009, Carlos Giesta passou a edição da revista para Gilberto Camanho, quando comemorou um percurso de 70 anos de publicação, com 44 volumes e 2.758 artigos publicados até abril, grande parte deles disponível na internet para qualquer profissional de saúde do mundo. O novo editor-chefe inicia a sua missão trazendo para a SBOT a administração da revista, onde já no primeiro ano apresenta espetacular crédito. A RBO tem agora seu local na sede da SBOT e a dedicação e eficiência de Diva Godoi e Carolina Widonsck. O corpo editorial passa por estruturação, as revisões são rápidas e on line, e o cargo de editor-chefe ganha um período preestabelecido entre os pares. Também busca com intensidade novas indexações.

A história da RBO é riquíssima. Resumi-la em texto tão pequeno é temerário. Porém, vale dizer que esta revista prestou e presta um espetacular serviço para as "duas pontas" da classe ortopédica brasileira - um local para publicar e um local para buscar informação. Bebemos, pois, água da mesma fonte.

Achilles de Araújo, Márcio Ibrahim de Carvalho, Donato D'Ângelo, Carlos Giesta e Gilberto Camanho, editoreschefes da RBO em diferentes épocas: obrigado pelo empenho, dedicação, amor à SBOT e à ciência. 